\title{
Impacts of recent cultivation on genetic diversity pattern of a medicinal plant, Scutellaria baicalensis (Lamiaceae)
}

\author{
Qing-Jun Yuan ${ }^{1 \dagger}$, Zhi-Yong Zhang ${ }^{2 \dagger}$, Juan Hu', Lan-Ping Guo ${ }^{1}$, Ai-Juan Shao'1, Lu-Qi Huang ${ }^{1 *}$
}

\begin{abstract}
Background: Cultivation of medicinal plants is not only a means for meeting current and future demands for large volume production of plant-based drug and herbal remedies, but also a means of relieving harvest pressure on wild populations. Scutellaria baicalensis Georgi (Huang-qin or Chinese skullcap) is a very important medicinal plant in China. Over the past several decades, wild resource of this species has suffered rapid declines and large-scale cultivation was initiated to meet the increasing demand for its root. However, the genetic impacts of recent cultivation on S. baicalensis have never been evaluated. In this study, the genetic diversity and genetic structure of 28 wild and 22 cultivated populations were estimated using three polymorphic chloroplast fragments. The objectives of this study are to provide baseline data for preserving genetic resource of $\mathrm{S}$. baicalensis and to evaluate the genetic impacts of recent cultivation on medicinal plants, which may be instructive to future cultivation projects of traditional Chinese medicinal plants.

Results: Thirty-two haplotypes of S. baicalensis (HapA-Y and Hap1-7) were identified when three chloroplast spacers were combined. These haplotypes constituted a shallow gene tree without obvious clusters for cultivated populations, suggesting multiple origins of cultivated S. baicalensis. Cultivated populations $\left(h_{T}=0.832\right)$ maintained comparable genetic variation with wild populations $\left(h_{T}=0.888\right)$, indicating a slight genetic bottleneck due to multiple origins of cultivation. However, a substantial amount of rare alleles (10 out of 25 haplotypes within wild populations) lost during the course of $\mathrm{S}$. baicalensis cultivation. The genetic differentiation for cultivated group $\left(G_{S T}=0.220\right)$ was significantly lower than that of wild group $\left(G_{S T}=0.701\right)$. Isolation by distance analysis showed that the effect of geographical isolation on genetic structure was significant in wild populations $(r=0.4346$, $P<0.0010)$, but not in cultivated populations $(r=0.0599, P=0.2710)$. These genetic distribution patterns suggest that a transient cultivation history and the extensive seed change among different geographical areas during the course of S. baicalensis cultivation.
\end{abstract}

Conclusions: Although cultivated S. baicalensis maintains comparable genetic diversity relative to wild populations, recent cultivation has still imposed profound impacts on genetic diversity patterns of the cultivated $S$. baicalensis populations, i.e., the loss of rare alleles and homogenization of cultivated populations. This study suggests that conservation-by-cultivation is an effective means for protecting genetic resources of $\mathrm{S}$. baicalensis, however, the wild resources still need to be protected in situ and the evolutionary consequences of extensive seed exchange mediated by human being should be monitored carefully.

\footnotetext{
* Correspondence: huangluqi@263.net

† Contributed equally

${ }^{1}$ Laboratory for Molecular Pharmaceutics, Institute of Chinese Materia

Medica, China Academy of Chinese Medical Sciences, Beijing 100700, China
} 


\section{Background}

The World Health Organization has estimated that more than $80 \%$ of the world's population depends on herbal medicine for primary healthcare needs [1]. Most materials used in herbal medicine and vitamin supplements are taken from wild plants and the rapid growing demands for medicinal plants, compounded by habitat loss, is exerting pressure on many species. With the increased realization that some wild species are being over-exploited, a number of governments and agencies are recommending that wild medicinal species should be brought into cultivation systems [2]. Cultivation of medicinal plants is not only a means for meeting current and future demands for large volume production of plant-based drug and herbal remedies, but also a means of relieving harvest pressure on wild populations $[3,4]$. In certain circumstances such as traditional agriculture, cultivation can serve as an important reservoir of genetic variability $[5,6]$.

However, cultivation can also have impacts on conservation, which need to be better understood [4]. Medicinal plant production through cultivation, for example, can reduce the incentives to conserve wild populations [7]. More importantly, founder effects and artificial selections for high yielding or pharmacologically standard individuals would probably result in a narrow genetic range of material in cultivation, resembling the genetic bottleneck during the domestication of cereal species [8]. Furthermore, seed exchange between farmers is much easier due to the highly developed transportation and commercial markets of modern times [9], but migration of seeds from their collection sites to other environments within a species range for cultivation may increase the risk of maladaptation [10,11]. Gene flow from maladapted cultivated individuals into adjacent native populations could also negatively affect adaptation to local environments [12].

Medicinal plants play inherent and prominent roles in the general health service in China. Due to longterm exploitation of wild medicinal herbs, many important Chinese traditional medicinal plants are becoming rare and endangered [13]. In order to protect the medicinal plant resources and meet the increasing demand for plant-based drug and herbal remedies, the most popular medicinal plants have been cultivated under the supervision of Chinese government or grown spontaneously by farmers [13]. Today, the cultivation areas of medicinal plants reach 5 million mus $(1 \mathrm{mu}=0.165$ acre $)$ [14]. The sharp increase in medicinal plant cultivation may greatly mitigate the pressure on the wild medicinal resources, but also impose profound impacts on the genetic diversity patterns of these medicinal plants. However, studies about genetic impacts of cultivation are mostly concentrated on economically valuable crops with long domestication history (see review in [8]), little is known regarding the genetic impacts of recent cultivation on medicinal plants (but see [15-18]). This issue becomes more important as wild gene pools of many medicinal species have decreased rapidly or become extinct. Domestic cultivation can not only meet the increasing demands of human consumption [15], but also represent a conservation-through-use approach for protecting genetic resources of medicinal plants [16].

Scutellaria baicalensis Georgi (Huang-qin or Chinese skullcap) is a perennial herb of the family Lamiaceae with fleshy root, branched stems, papery leaves, purplered to blue flowers, and black-brown ovoid nutlets [19]. Root of this herb (Radix Scutellariae) is a very important Chinese Materia Medica that was first recorded in Shen Nong Ben Cao Jing in ca. 100 BC [20] and officially listed in the Chinese Pharmacopoeia [21]. As one of the most important heat-clearing and dehumidifying drugs in traditional Chinese medicine, Radix Scutellariae has been widely used in the treatment of hepatitis, jaundice, tumor, leukemia, hyperlipaemia, arteriosclerosis, diarrhea, and inflammatory diseases [22-24]. Huang-qin is pollinated by bees and flies, and propagated by seeds [25]. The wild populations of S. baicalensis is widely distributed in Nei mongol, Heilongjiang, Jilin, Liaoning, Hebei, Shandong, Jiangsu, Henan, Hubei, Shanxi, Shaanxi, and Gansu provinces from Northeast to Northwest China and adjacent areas including Mongolia, Russia, Korea and Japan [19]. This species often appears in grassland, sunny grassy slopes and shrubbery or forest habitats (from 12 to $2000 \mathrm{~m}$ ) with a cold-dry climate [19]. Over the past several decades, the wild resource of S. baicalensis has suffered rapid declines, and thus was listed as a class III conserved medicinal plant in China [26]. To meet the increasing demand for its root, largescale cultivation programs have been initiated in China since 1958 [27]. Because S. baicalensis is a newly-cultivated species and there are still plenty of wild populations, this medicinal species may represent an ideal model to evaluate the impacts of recent cultivation on the genetic diversity pattern of medicinal plants. Three polymorphic chloroplast fragments were chosen for population genetic analyses in this study because chloroplast markers are more sensitive than nuclear markers to demographic fluctuations such as cultivation bottlenecks resulting from smaller effective population sizes $\left(N_{\mathrm{e}}\right)$ [28]. In addition, chloroplast markers are powerful tools for tracing the maternal origins of cultivated populations and seed exchange among populations, which are of important relevance to genetic resource conservation $[6,29]$. The objectives of this study were 
to: 1) quantify the amount of genetic variation in wild and cultivated populations of $S$. baicalensis; 2) compare the genetic structure in wild and cultivated populations of $S$. baicalensis; 3) evaluate the impacts of recent cultivation on the genetic diversity pattern of S. baicalensis; and 4) unravel the meaning of recent cultivation on medicinal plant germplasm conservation.

\section{Methods}

\section{Sampling}

A total of 602 and 451 individuals of S. baicalensis representing 28 wild and 22 cultivated populations were collected from Northeast to Northwest China, respectively (Table 1, Fig. 1). Seventeen to twenty-four individuals were sampled for each population. Twenty-two Scutellaria rehderiana Diels individuals were sampled from a wild population of Weiyuan county in Gansu province (WYW) as an outgroup (Table 1, Fig. 1a). Leaves for DNA extraction were dried with silica gel. Voucher specimens were deposited in herbaria of Institute of Chinese Materia Medica (CMMI), China Academy of Chinese Medical Sciences. The precise geographic location of each sampled population was determined using a Garmin GPS unit (Table 1).

\section{DNA extraction, amplification and sequencing}

Dried leaves were milled by using RETSCH Mixer Mill (MM301). Genomic DNA was extracted using a modified cetyltrimethyl ammonium bromide (CTAB) protocol [30]. The universal primers described in Hamilton [31] and Sang et al. [32] were used for screening polymorphic cpDNA fragments. After preliminary screening of eight chloroplast fragments, we chose $a t p \mathrm{~B}-r b c \mathrm{~L}$, trnL-trn $\mathrm{F}$ and $p s b \mathrm{~A}-\operatorname{trn} \mathrm{H}$ intergenic spacers for the full survey because they contained the most polymorphic sites. PCR amplification was performed in a TC-512 thermocycler (Techne, England) programmed for an initial $240 \mathrm{~s}$ at $94^{\circ} \mathrm{C}$, followed by 30 cycles of $45 \mathrm{~s}$ at $94^{\circ} \mathrm{C}, 30 \mathrm{~s}$ at $55^{\circ} \mathrm{C}(a t p \mathrm{~B}-r b c \mathrm{~L}), 54^{\circ} \mathrm{C}(\operatorname{trn} \mathrm{L}-t r n \mathrm{~F})$ or $58^{\circ} \mathrm{C}(p s b \mathrm{~A}-t r n \mathrm{H}), 90 \mathrm{~s}$ at $72^{\circ} \mathrm{C}$, and a final $240 \mathrm{~s}$ at $72^{\circ} \mathrm{C}$. Reactions were carried out in a volume of $20 \mu \mathrm{L}$ containing $2.0 \mathrm{~mm} / \mathrm{L} \mathrm{MgCl}_{2}, 0.5 \mu \mathrm{m} / \mathrm{L} \mathrm{dNTP}, 10 \times$ buffer, $2.5 \mu \mathrm{m} / \mathrm{L}$ primer, $1 \mathrm{U}$ Taq DNA and $20 \mathrm{ng}$ DNA template. Sequencing reactions were conducted with the forward or reverse primers of the PCR using the DYEnamic ET Terminator Kit (Amersham Pharmacia Biotech), following the manufacturer's protocol. Sequencing was performed on a HITACHI 3130 Genetic Analyzer (Hitachi High-Technologies Corporation, Tokyo Japan) after the reaction product was purified through precipitation with $95 \%$ ethanol and $3 \mathrm{M}$ sodium acetate ( $\mathrm{pH}$ 5.2).
Table 1 Details of sample locations, sample sizes in 28 wild and 22 cultivated populations of Scutellaria baicalensis and 1 wild population of Scutellaria rehderiana

\begin{tabular}{|c|c|c|c|c|c|c|}
\hline Province & County & $\mathbf{P}$ & Lat. & Long. & Alt.(m) & $\mathrm{N}$ \\
\hline Neimenggu & Eerguna & EGW & $50.42^{\circ}$ & $119.51^{\circ}$ & 564.7 & 20 \\
\hline Neimenggu & Linxi & LXW & $44.05^{\circ}$ & $117.76^{\circ}$ & 1212 & 24 \\
\hline Neimenggu & Keshiketeng & KKW & $43.28^{\circ}$ & $117.23^{\circ}$ & 1399 & 22 \\
\hline Neimenggu & Guyang & GYW & $41.20^{\circ}$ & $110.60^{\circ}$ & 1854 & 24 \\
\hline Neimenggu & Kalaqin & KQLC & $42.90^{\circ}$ & $118.50^{\circ}$ & 691.2 & 20 \\
\hline Neimenggu & Kalaqin & KQIC & $42.90^{\circ}$ & $118.76^{\circ}$ & 691.2 & 24 \\
\hline Heilongjiang & Huma & HMW & $51.93^{\circ}$ & $126.43^{\circ}$ & 288.3 & 24 \\
\hline Heilongjiang & Duerbote & DMW & $46.51^{\circ}$ & $124.59^{\circ}$ & 146.2 & 24 \\
\hline Heilongjiang & Luobei & LBC & $47.91^{\circ}$ & $130.72^{\circ}$ & 184.2 & 17 \\
\hline Jilin & Baicheng & BCW & $45.90^{\circ}$ & $122.42^{\circ}$ & 240.8 & 19 \\
\hline Jilin & Yanji & YJW & $42.92^{\circ}$ & $129.60^{\circ}$ & 302.1 & 21 \\
\hline Jilin & Changchun & $\mathrm{CCC}$ & $43.87^{\circ}$ & $125.27^{\circ}$ & 241 & 19 \\
\hline Liaoning & Jianchang & $\mathrm{JCW}$ & $40.82^{\circ}$ & $119.78^{\circ}$ & 362 & 22 \\
\hline Liaoning & Jinzhou & JZW & $39.13^{\circ}$ & $121.70^{\circ}$ & 12 & 20 \\
\hline Liaoning & Yixian & $Y X C$ & $41.53^{\circ}$ & $121.23^{\circ}$ & 61 & 22 \\
\hline Hebei & Chengde & CD1W & $41.20^{\circ}$ & $117.94^{\circ}$ & 58 & 18 \\
\hline Hebei & Chengde & $\mathrm{CD} 1 \mathrm{C}$ & $41.20^{\circ}$ & $117.94^{\circ}$ & 58 & 17 \\
\hline Hebei & Chengde & CD2W & $40.20^{\circ}$ & $117.94^{\circ}$ & 60 & 23 \\
\hline Hebei & Chengde & $\mathrm{CD} 2 \mathrm{C}$ & $40.20^{\circ}$ & $117.73^{\circ}$ & 60 & 21 \\
\hline Hebei & Kuancheng & $\mathrm{KCW}$ & $40.62^{\circ}$ & $118.47^{\circ}$ & 304 & 17 \\
\hline Hebei & Kuancheng & KCC & $40.61^{\circ}$ & $118.49^{\circ}$ & 304 & 19 \\
\hline Hebei & Luanping & LPW & $40.95^{\circ}$ & $117.53^{\circ}$ & 523 & 18 \\
\hline Hebei & Luanping & LPC & $40.93^{\circ}$ & $117.33^{\circ}$ & 523 & 20 \\
\hline Hebei & Chicheng & CCW & $40.92^{\circ}$ & $115.82^{\circ}$ & 1100 & 22 \\
\hline Beijing & Yanqing & YQ1W & $40.47^{\circ}$ & $115.97^{\circ}$ & 900 & 19 \\
\hline Beijing & Yanqing & YQ2W & $40.52^{\circ}$ & $115.78^{\circ}$ & 1300.6 & 22 \\
\hline Beijing & Yanqing & YQC & $40.52^{\circ}$ & $115.78^{\circ}$ & 600 & 23 \\
\hline Shandong & Yantai & YTW & $37.55^{\circ}$ & $121.52^{\circ}$ & 25 & 24 \\
\hline Shandong & Jinan & JNC & $36.64^{\circ}$ & $117.36^{\circ}$ & 200 & 20 \\
\hline Shandong & Juxian & JUXC & $35.90^{\circ}$ & $118.97^{\circ}$ & 179 & 19 \\
\hline Jiangsu & Jurong & $J R C$ & $31.87^{\circ}$ & $119.22^{\circ}$ & 22 & 24 \\
\hline Henan & Huixian & HXW & $35.46^{\circ}$ & $113.77^{\circ}$ & 863 & 22 \\
\hline Henan & Songxian & SXW & $34.22^{\circ}$ & $111.91^{\circ}$ & 864.5 & 19 \\
\hline Henan & Songxian & $S X C$ & $34.18^{\circ}$ & $111.97^{\circ}$ & 539.3 & 21 \\
\hline Hubei & Fangxian & FXC & $33.06^{\circ}$ & $110.07^{\circ}$ & 918 & 21 \\
\hline Shanxi & Wutai & WTW & $38.83^{\circ}$ & $113.36^{\circ}$ & 1148 & 24 \\
\hline Shanxi & Fenyang & FYW & $37.42^{\circ}$ & $111.65^{\circ}$ & 1588 & 23 \\
\hline Shanxi & Fenyang & FYC & $37.35^{\circ}$ & $111.77^{\circ}$ & 947 & 21 \\
\hline Shanxi & Lingchuan & LCW & $35.98^{\circ}$ & $113.49^{\circ}$ & 1406 & 21 \\
\hline Shanxi & Lingchuan & LCC & $35.95^{\circ}$ & $111.72^{\circ}$ & 1363 & 22 \\
\hline Shanxi & Jiangxian & JXW & $35.39^{\circ}$ & $111.61^{\circ}$ & 854.5 & 23 \\
\hline Shanxi & Jiangxian & $J X C$ & $35.47^{\circ}$ & $111.46^{\circ}$ & 545 & 20 \\
\hline Shaanxi & Huanglong & HLW & $35.59^{\circ}$ & $109.88^{\circ}$ & 1218 & 24 \\
\hline Shaanxi & Huanglong & $\mathrm{HLC}$ & $35.59^{\circ}$ & $109.88^{\circ}$ & 1160 & 18 \\
\hline Shaanxi & Shanyang & SYW & $33.56^{\circ}$ & $109.89^{\circ}$ & 949.0 & 19 \\
\hline Shaanxi & Taibai & TBW & $34.06^{\circ}$ & $107.30^{\circ}$ & 1682 & 24 \\
\hline Shaanxi & Taibai & $\mathrm{TBC}$ & $34.04^{\circ}$ & $107.30^{\circ}$ & 1565 & 22 \\
\hline
\end{tabular}


Table 1: Details of sample locations, sample sizes in 28 wild and 22 cultivated populations of Scutellaria baicalensis and 1 wild population of Scutellaria rehderiana (Continued)

\begin{tabular}{lllllll}
\hline Gansu & Heshui & HSW & $36.12^{\circ}$ & $108.67^{\circ}$ & 1121 & 20 \\
Gansu & Weiyuan & WYW $^{*}$ & $35.15^{\circ}$ & $104.21^{\circ}$ & 2115 & 22 \\
Gansu & Weiyuan & WYC & $35.15^{\circ}$ & $104.21^{\circ}$ & 2090 & 21 \\
Gansu & Zhangxian & ZXC & $34.60^{\circ}$ & $104.60^{\circ}$ & 2065 & 20
\end{tabular}

Abbreviations: P, population code; Lat., latitude; Long., longitude; Alt., altitude; $\mathrm{N}$, number of sampled individuals; the last letter of population code: $\mathrm{W}$, wild C, cultivated; *: Scutellaria rehderiana.

\section{Data analysis}

Sequences were aligned using Clustal_X version 1.81 [33], and all indels were coded as substitutions following Caicedo and Schaal [34]. All individuals were characterized for cpDNA haplotype. Sequence variation was tested for deviations from neutrality by Tajima's $D$ statistic [35], and by Fu and Li's $D^{*}$ and $F^{*}$ statistics [36] using DNASP 4.00 [37]. A haplotype network depicting the mutational relationships among distinct haplotypes was drawn following the principle of parsimony by TCS version 1.13 [38,39], positing S. rehderiana as outgroup. The geographical distribution of haplotypes was plotted on a map of China using Arcmap 8.3 (ESRI, Inc.). Significant difference of haplotype frequencies between wild and cultivated populations was quantified using $x^{2}$ test. Total diversity $\left(h_{\mathrm{T}}\right)$, within-population diversity $\left(h_{\mathrm{S}}\right)$ and level of population differentiation $\left(G_{\mathrm{ST}}\right)$ were calculated using the program HAPLONST, treating wild and cultivated populations as separate groups. The significance of the parameter comparisons (Number of haplotype; Total diversity, $h_{\mathrm{T}}$; Within-population diversity, $h_{\mathrm{S}}$; Population differentiation, $G_{\mathrm{ST}}$ ) between wild and cultivated groups were estimated by $x^{2}$ test and Wilcoxon two-group tests, being implemented in the statistical package SPSS17.0 (SPSS Inc.).

Hierarchical structure of genetic variation in S. baicalensis was determined by an analysis of molecular variance (AMOVA) with ARLEQUIN version 2.000, partitioning genetic variance into three levels: among groups (cultivated and wild groups), among-population within groups, and within-population. Genetic differentiation between cultivated and wild groups was also evaluated using DNASP 4.00 [37]. To examine the effect of geographical distance on genetic structure, correlations between pairwise genetic distances (Kimura 2-parameter distance generated with Kimura's two parameter model in MEGA 3) [40-42] and pairwise geographic distances were tested using a Mantel test implemented by Isolation By Distance Web Service [43].

\section{Results}

Sequence characteristics of three chloroplast intergenic spacers

The aligned sequences of $a t p \mathrm{~B}-r b c \mathrm{~L}, \operatorname{trn} \mathrm{L}-\operatorname{trn} \mathrm{F}$, and psbA-trn $\mathrm{H}$ spacers in S. baicalensis and S. rehderiana were 768, 799 and 502 base pairs in length, respectively. There were 13,7 , and 14 polymorphic sites (including substitutions and indels) for the three spacers, respectively (Table 2). Because sequencing poly-N regions could easily lead to homoplasies due to polymerase error [44], the short sequence repeats (poly-C) between 502-508 bp of trnL-trnF were not treated as polymorphic sites and were removed from subsequent analyses. Sequence divergence, as measured with Kimura two-parameter algorithm, ranged from $0.000 \%$ to $0.262 \%, 0.000 \%$ to $0.257 \%$, and $0.000 \%$ to $0.559 \%$ for $a \operatorname{ta} \mathrm{B}-r b c \mathrm{~L}$, trn $\mathrm{L}-\operatorname{trn} \mathrm{F}$, and $p s b \mathrm{~A}-\operatorname{trn} \mathrm{H}$, respectively. Sequences of the three spacers conformed to the expectation of neutrality by Tajima's criterion $(a t p \mathrm{~B}-r b c \mathrm{~L}: D=-1.53470,0.10>P>0.05$; $\operatorname{trn} \mathrm{L}-\operatorname{trn} \mathrm{F}$ : $D=-1.31009, P>0.10$; and $p s b \mathrm{~A}-\operatorname{trn} \mathrm{H}: D=-1.38479$, $P>0.10)$ and $\mathrm{Fu}$ and Li's criterion $\left(\operatorname{atpB}-r b c \mathrm{~L}: D^{*}=\right.$ -1.66525, $P>0.10 ; F^{*}=-1.79736, P>0.10 ; \operatorname{trnL}-\operatorname{trnF}$ : $D^{*}=-1.40980, P>0.10 ; F^{*}=-1.51361, P>0.10$; and psbA-trnH: $D^{*}=-1.28584, P>0.10 ; F^{*}=-1.48316, P>$ $0.10)$. The pooled sequences of the three spacers also complied with the expectation of neutrality $(D=$ -0.90417, $P>0.10 ; D^{*}=-1.33584, P>0.10 ; F^{*}=$ $-1.40744, P>0.10)$. The sequences of nine $a t p \mathrm{~B}-r b c \mathrm{~L}$, eight $\operatorname{trn} \mathrm{L}-\operatorname{trn} \mathrm{F}$, and thirteen $p s b \mathrm{~A}-\operatorname{trn} \mathrm{H}$ haplotypes have been deposited in GenBank databases [GenBank: GQ374124-GQ374155]. Thirty-two haplotypes of $S$. baicalensis (HapA-Y and Hap1-7) and 2 haplotypes of S. rehderiana (HapZ1-Z2) were identified when atpB-

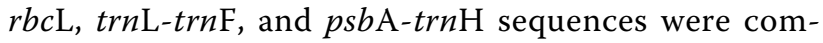
bined (Table 2).

\section{Haplotype network and distribution}

In the haplotype network (Fig. 2), the 32 haplotypes of $S$. baicalensis and 2 haplotypes of $S$. rehderiana differed by at least 10 mutations. The genealogical structure of 32 haplotypes of S. baicalensis presented a shallow gene tree with three obvious centers: HapG, HapB and HapC, which connected to other 10,6 , and 4 haplotypes by just one mutation, respectively. Additionally, both HapB and HapC connected to HapG by one mutation. Exceptionally, several haplotypes detected only in wild populations were relatively remote to the three centers of the shallow gene tree, such as HapA, H, M, T, W, X, and Y. The haplotypes of cultivated S. baicalensis (symbolized by ovals and circles) evenly distributed across the haplotype network, not showing any clusters. 


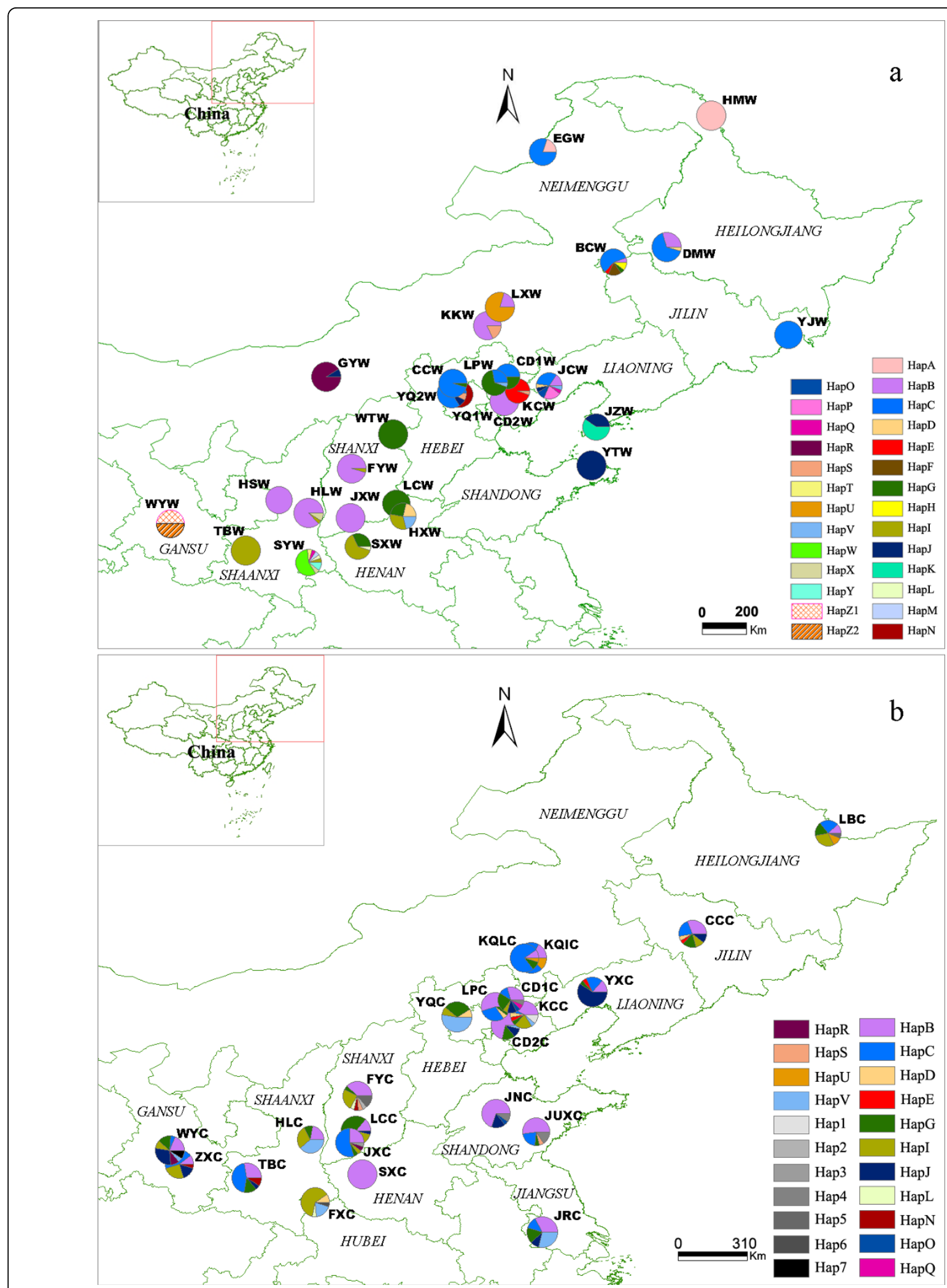

Figure 1 Geographic distribution and frequencies of chloroplast haplotypes in wild Scutellaria baicalensis and Scutellaria rehderiana (WYW) (a) and cultivated Scutellaria baicalensis (b) populations. Population abbreviations are the same as Table 1. The pie sizes of populations are proportional to their sample sizes. 


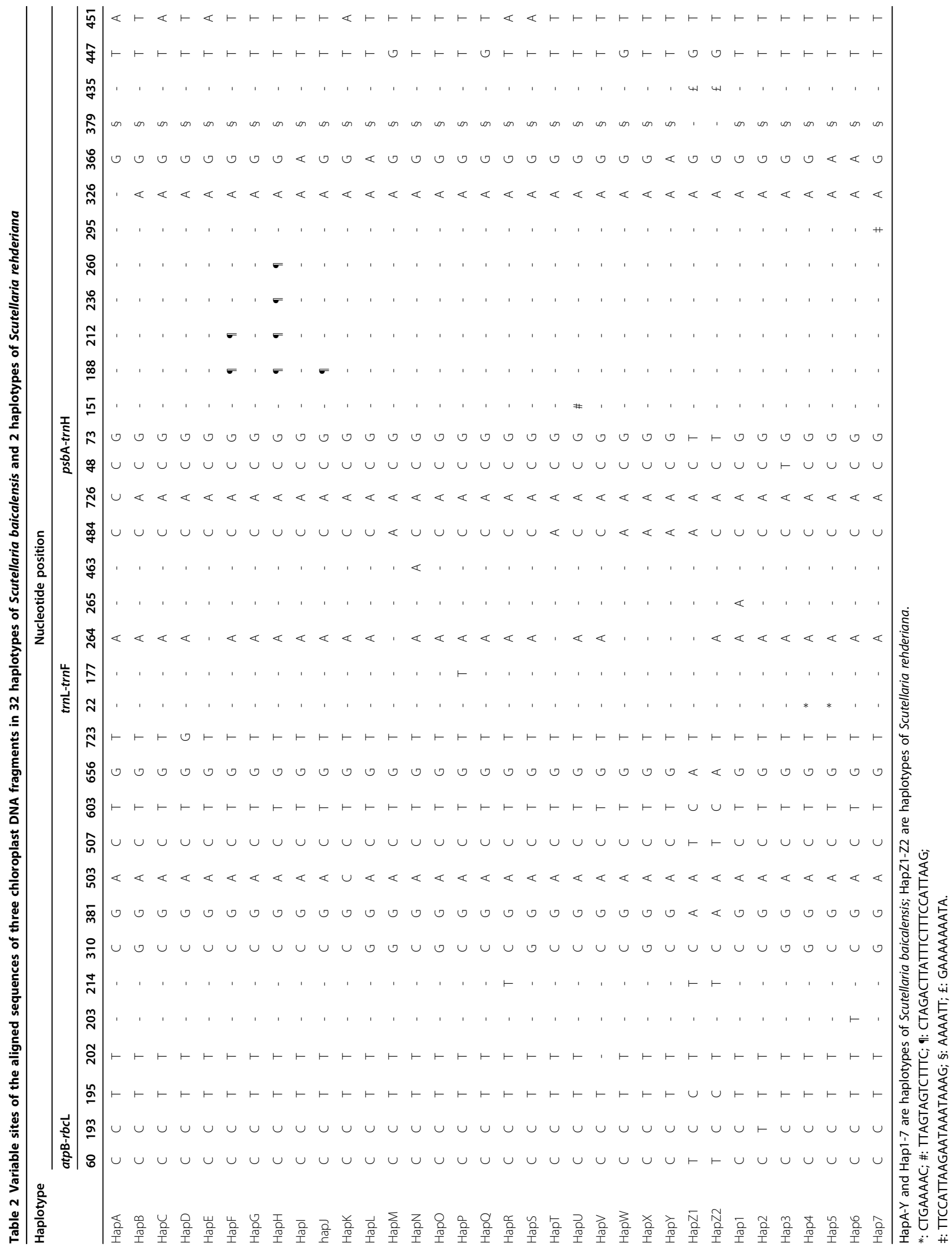




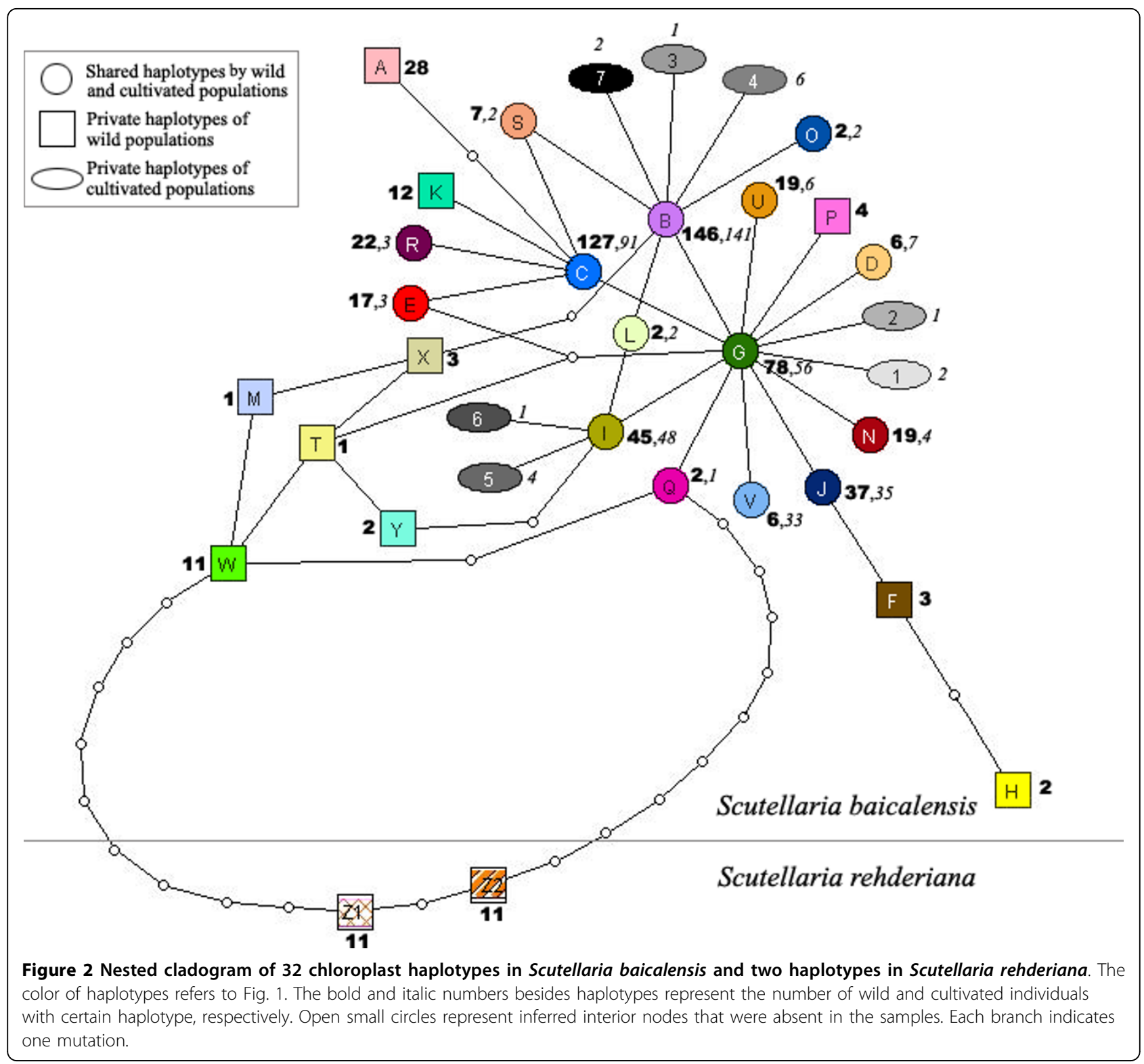

Haplotype frequencies in each population and geographical distribution are presented in Fig. 1, Additional file 1, and 2. By visual inspection of Fig. 1, the haplotype distributions of wild and cultivated populations were in sharp contrast. The most noticeable pattern was that haplotypes among wild populations were much more structured than those among cultivated populations. For example, HapG in wild populations (WTW, LCW, LPW, CD1W, SXW, and HXW) was mainly restricted to the central range of this species, whereas this haplotype occurred in 17 of 22 cultivated populations across the whole range. Another conspicuous phenomenon was that many wild populations (10 out of 28 ) were fixed by one unique haplotype, but in cultivated populations, only SXC was fixed by one haplotype (i.e., most cultivated populations characterized by multiple haplotypes).

\section{Genetic diversity and genetic structure}

Of the 32 haplotypes detected in S. baicalensis, 25 (78\% of the total number of haplotypes) were recovered in wild populations and 22 (69\% of the total number of haplotypes) were carried by cultivated individuals (Fig. 3, Table 3). Fifteen haplotypes (47\% of the total number of haplotypes) were shared by wild and cultivated populations (Fig. 3). Ten haplotypes were found in wild populations but not in cultivated ones, and seven were found exclusively in cultivated populations (Fig. 3). By comparison, the number of haplotypes and the 


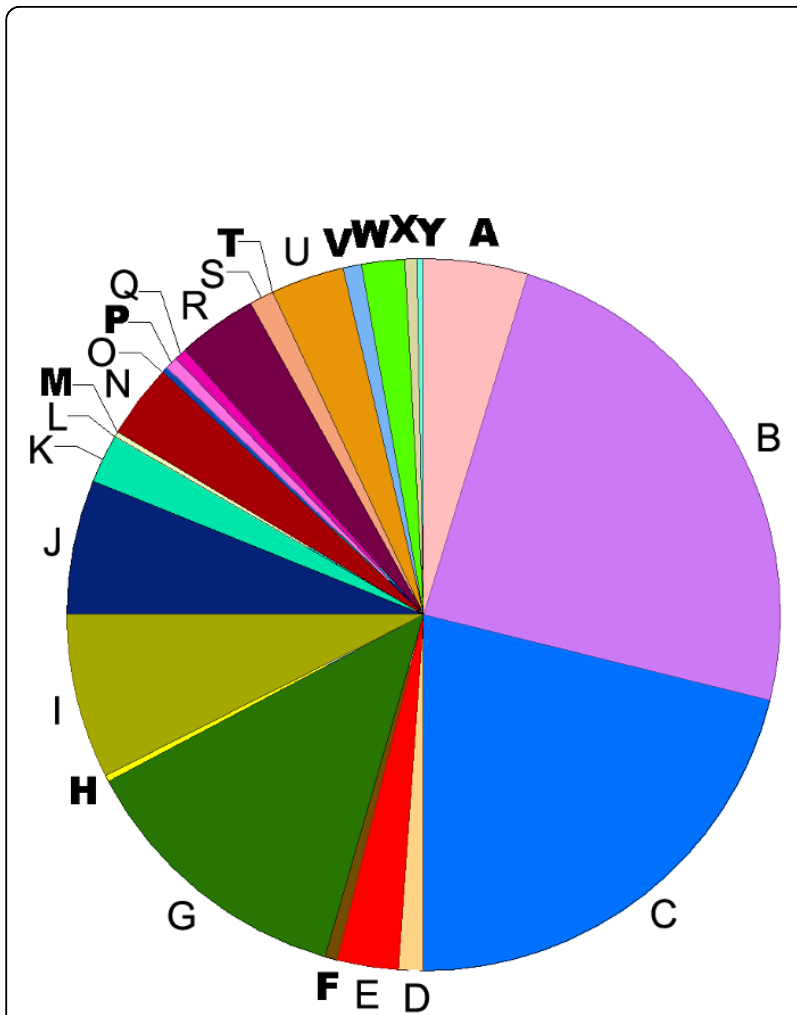

Wild

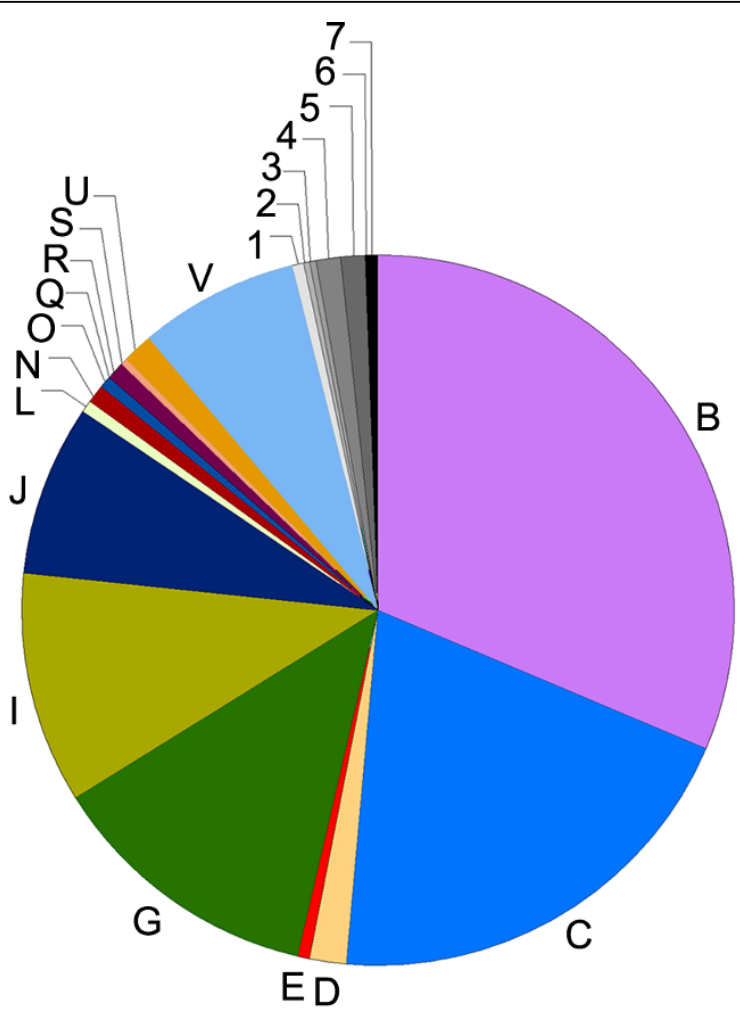

Cultivated

Figure 3 The relative proportions of different chloroplast haplotypes found in wild and cultivated Scutellaria baicalensis. The color of haplotypes refers to Fig. 1. Twenty-five haplotypes were found in wild populations and twenty-two haplotypes were recovered in cultivated populations. Fifteen haplotypes (thin letters) are shared by wild and cultivated groups. Ten (bold letters) and seven (numbers 1-7) haplotypes are specific to wild and cultivated groups, respectively.

relative abundance of each haplotype have slightly changed under the anthropogenic influence during the course of cultivation (Fig. 3, see Additional file 1,2). However, the change of haplotype frequencies between wild and cultivated groups was not significant by $x^{2}$ test $(P=0.733$; Table 3$)$, because cultivated and wild groups only differed in rare haplotypes (Fig. 3). As indicated by the haplotype frequencies within population (Fig. 1, see Additional file 1,2), the within-population diversity

Table 3 Comparisons of genetic diversity and genetic structure between wild and cultivated Scutellaria baicalensis populations

\begin{tabular}{lccc}
\hline Parameter & wild & cultivated & $\boldsymbol{P}$ \\
\hline Number of haplotype & 25 & 22 & $0.733 \dagger$ \\
Total diversity, $h_{\mathrm{T}}$ & $0.888(0.0287)$ & $0.832(0.0234)$ & $>0.05 \ddagger$ \\
Within-population diversity, $h_{S}$ & $0.265(0.0526)$ & $0.649(0.0425)$ & $<\mathbf{0 . 0 0 1 \neq}$ \\
Population differentiation, $G_{S T}$ & $0.701(0.0594)$ & $0.220(0.0449)$ & $<\mathbf{0 . 0 0 1 \neq}$
\end{tabular}

Parameters of population subdivision are followed by standard error in parentheses.

Statistically significant comparisons are highlighted in bold type. $\dagger: x^{2}$ test; $\neq$ : Wilcoxon two-group test.
$\left(h_{\mathrm{S}}=0.649\right)$ of cultivated $S$. baicalensis was significantly higher than that $\left(h_{\mathrm{S}}=0.265\right)$ of wild Huang-qin $(P<$ 0.001 , Wilcoxon two-group test; Table 3 ), although the total haplotype diversity was similar between cultivated and wild groups $\left(h_{\mathrm{T}}=0.832\right.$ in cultivated vs $h_{\mathrm{T}}=0.888$ in wild, $P>0.05$, Wilcoxon two-group test; Table 3).

Consistent with the haplotype distribution (Fig. 1), population subdivision of wild populations $\left(G_{\mathrm{ST}}=0.701\right)$ was significantly higher than that of the cultivated $\left(G_{\mathrm{ST}}=\right.$ 0.220; $P<0.001$, Wilcoxon two-group test; Table 3). Mantel test analyses showed that genetic distance was significantly correlated with geographical distance $(r=$ $0.4346, P<0.0010$; Fig. 4 ) in wild populations, however, this pattern was not recovered in cultivated populations $(r=0.0599, P=0.2710$; Fig. 4). AMOVA analysis showed that little genetic variation occurred between cultivated and wild populations $(0.09 \%, P<0.001)$, and most genetic variance were among populations $(56.61 \%)$ and within populations (43.30\%; Table 4). The genetic differentiation $\left(F_{\mathrm{ST}}=0.022\right)$ between the cultivated and wild groups calculated by DNASP 4.00 was well consistent with the result of AMOVA analysis. 


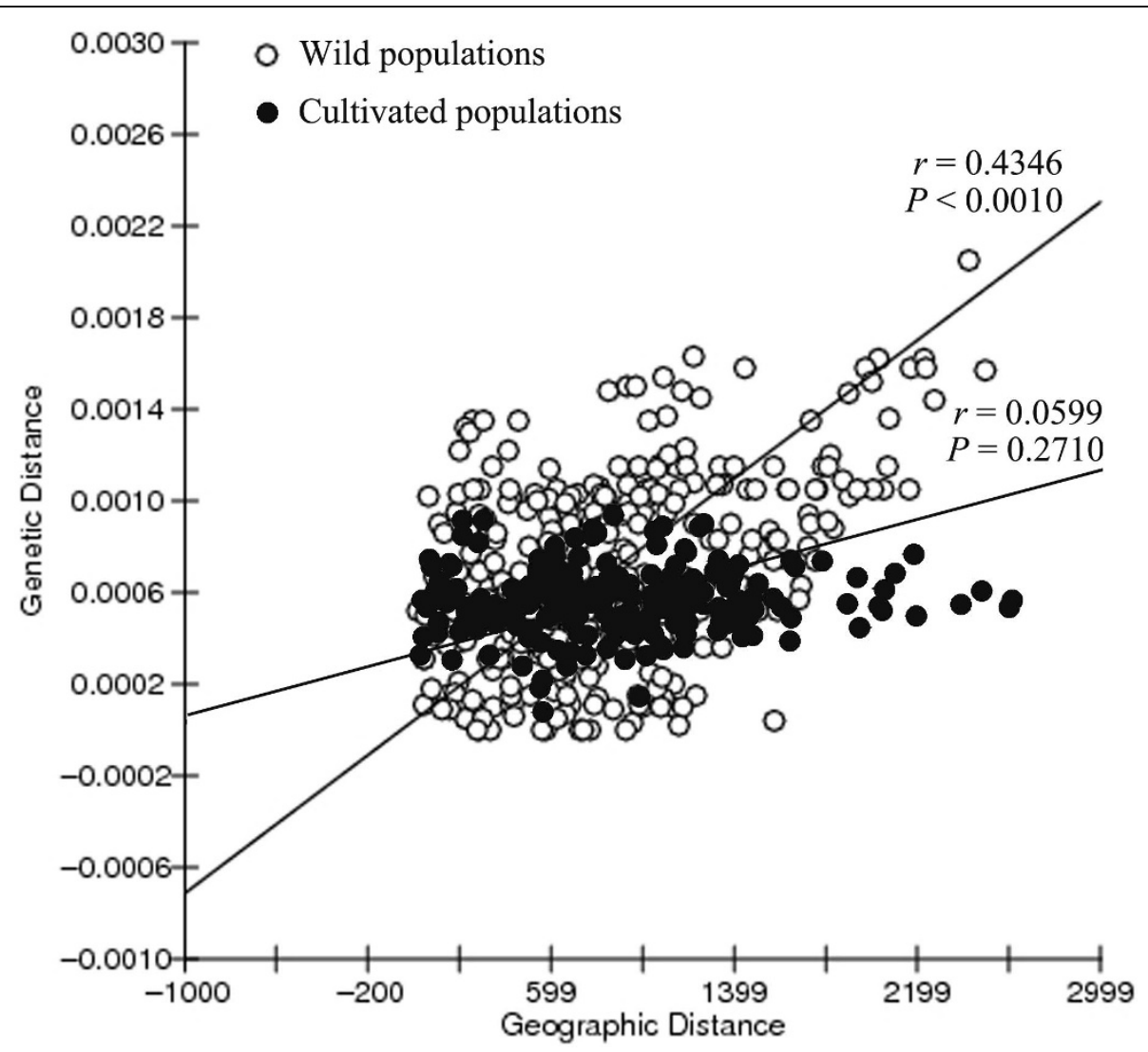

Figure 4 Scatterplots of genetic distances (Kimura 2-parameter distance) against geographical distances (kilometres) separating each pairwise combination of populations within wild and cultivated Scutellaria baicalensis.

Table 4 Hierarchical analysis of molecular variance for 50 populations of Scutellaria baicalensis

\begin{tabular}{llllllll}
\hline Hierarchical level & $\begin{array}{l}\text { Deg. of } \\
\text { freedom }\end{array}$ & $\begin{array}{l}\text { Sum of } \\
\text { squares }\end{array}$ & $\begin{array}{l}\text { Variance } \\
\text { components }\end{array}$ & $\begin{array}{l}\text { Percentage } \\
\text { of variance }\end{array}$ & F-statistics & P-value* \\
\hline Among groups & 1 & 7.740 & 0.00055 & 0.09 & $F_{\text {CT }}=0.00091$ & $<0.001$ \\
$\begin{array}{l}\text { Among populations } \\
\text { within groups }\end{array}$ & 48 & 356.792 & 0.34067 & 56.61 & $F_{\text {ST }}=0.56698$ & $<0.001$ \\
\begin{tabular}{l} 
Within populations \\
\hline
\end{tabular} & 1003 & 261.380 & 0.26060 & 43.30 & $F$ FS $=0.56659$ & $<0.001$ \\
\hline
\end{tabular}

All populations are partitioned into cultivated and wild groups.

*: Significance calculated using 1023 permutations.

\section{Discussion}

Slight reduction of genetic diversity and little change of genetic composition in cultivated $S$. baicalensis

Cultivation of wild plants always produces genetic bottlenecks and thus results in loss of genetic diversity due to founder effects and unconscious or conscious selections [8]. For example, only $23 \%$ of the total chloroplast haplotypes detected in Oryza rufipogon and O. sativa were recovered in the cultivated rice [29]. However, concerns about the impacts of cultivation bottlenecks are mostly concentrated on economically valuable crops with long domestication history, little is known about the genetic impacts of recent cultivation on medicinal plants. In this study, slight reduction of genetic diversity and little change of genetic composition during the cultivation of S. baicalensis were revealed (Fig. 3, Table 3). These results are in sharp contrast to most crop species with long cultivation histories and may be explained by the large initial population size of cultivated S. baicalensis, the short cultivation history, and weak artificial selection pressure.

The strength of genetic bottleneck during cultivation is determined by two interacting factors: the size of the bottlenecked population and the bottleneck's duration $[8,45]$. Intuitively, cultivated plants of multiple origins (multiple places and multiple events) would hold larger 
population size and thus most likely maintain greater genetic diversity [46]. This point has been supported by a handful of empirical studies (e.g., Magnolia officinalis var. biloba [16]; einkorn [47]; Spondias purpurea [6]), although artificial selection and founder-event-induced genetic drift over the course of subsequent domestication are capable of reducing genetic diversity in multiple-origin plants (e.g. $[29,44])$. In this study, different lines of evidence support that cultivated S. baicalensis could have originated from different places for multiple times, resulting in large initial population size during cultivation. First, a large proportion of haplotypes (47\% of the total number of haplotypes) were found in both wild and cultivated populations and these shared haplotypes were recovered from different wild populations (Fig. 1, 3). This even distribution pattern of shared alleles in cultivated and wild populations strongly suggests that genetically distinct individuals from different geographic regions were taken into cultivation and subsequently distributed by humans $[44,48]$. Second, no cluster of cultivated haplotypes was observed in the haplotype network (Fig. 2), indicating that cultivated S. baicalensis is of multiple origins because crops of single origin often form a monophyletic clade in a phylogenetic tree that includes wild progenitors [46].

According to the tremendous literature of traditional Chinese medicine, Huang-qin was rarely cultivated until the foundation of the People's Republic of China in 1949 [27]. However, over the past several decades, the wild resource of this species declined rapidly because of over-exploitation. To meet the increasing demand for the root of this species, large-scale cultivation began since 1958 [27]. Such a short cultivation history, in combination with the large initial population size, may be unlikely to produce a strong genetic bottleneck, resulting in significant reduction of genetic diversity and change in genetic composition of cultivated S. baicalensis. Other population genetic studies on recently-cultivated Chinese medicinal plants also suggested that high genetic diversity in cultivated populations is due to their slight cultivation bottlenecks [15-17], which provides genetic raw materials for breeding new varieties of medicinal plants.

Apart from demographic factors, selection is another important element in shaping the genetic diversity pattern of cultivated species. Artificial selection for desired traits can decrease genetic diversity of target loci and their linked loci beyond that caused by the bottlenecks [8]. The fact that only few cultivars of S. baicalensis have been officially registered in China [49] suggests that artificial selection on this cultivated medicinal herb is weak, which resulting in only slight reduction of genetic diversity during cultivation. In addition, the relaxation in selective constraint under cultivated conditions might also contribute to the high genetic diversity within cultivated $S$. baicalensis populations because relaxation of selective constraint allow the accumulation of mutations that may otherwise be deleterious in nature [50,51]. However, considering the short cultivation history of $S$. baicalensis, the relaxation of selective constraint might play limited role in molding the genetic diversity pattern of cultivated Huang-qin.

\section{Extensive seed exchange among cultivated S. baicalensis populations}

Cultivation impacts not only the amount of genetic variation contained in cultivated populations but also the structure of this variation $[48,52,53]$. In this study, we found that the cultivated $S$. baicalensis populations displayed a lower proportion of genetic variation among populations $\left(G_{\mathrm{ST}}=0.220\right)$ than wild populations $\left(G_{\mathrm{ST}}=\right.$ 0.701). In addition, Mantel test analyses showed that the effect of geographical isolation on genetic structure was significant in wild populations $(r=0.4346, P<0.0010$; Fig. 4), but not in cultivated populations $(r=0.0599$, $P=0.2710$; Fig. 4). These results suggest that cultivation has imposed a profound impact on the genetic structure of cultivated S. baicalensis. However, these findings run contrary to the results of Hamrick and Godt [53], which reported that the mean value of genetic differentiation among crop species $\left(G_{\mathrm{ST}}=0.339\right)$ is higher than that of noncrop species $\left(G_{\mathrm{ST}}=0.212\right)$.

Two possible reasons may account for the unusual pattern revealed in S. baicalensis. First, there has been insufficient time for artificial selection and breeding to exert influence on the genetic divergence of cultivated S. baicalensis. The crop species (i.e. Zea mays, Hordeum vulgare, etc.) summarized in the review of Hamrick and Godt [53] almost have long histories of cultivation. Long-term artificial selection and inbreeding within cultivars imposed by plant breeding could have resulted in the genetic variation occurring generally among cultivars $[52,54,55]$. However, for $S$. baicalensis, due to its short cultivation history, artificial selection and breeding cultivars are unlikely to promote the genetic differentiation of cultivated populations as suggested by few S. baicalensis cultivars in China [49]. This fact indicates that standard industrial cultivation, a practice possibly imposing high artificial selection pressure on medicinal herbs, has not been established for S. baicalensis [4].

Second, homogenization among cultivated populations as well as high within-population diversity could have been facilitated by extensive seed exchange among different geographic locations due to highly developed transportation and commercial markets of modern times. A study of pepino (Solanum muricatum), a herbaceous Andean domesticate, suggested that human interchange among communities and countries in the 
past 50 years or so has considerably weakened the geographic differentiation of genetic diversity of cultivated pepinos [9]. For Chinese cultivated medicinal plants, such as Coptis chinensis, Magnolia officinalis, the bulking and mixing of seeds from different geographic locations are the common practice, which produced lower genetic differentiation among cultivated populations $[16,17]$. However, the genetic markers (ISSR and AFLP) used in those studies are biparentally transmitted, incapable of ruling out the effects of seed flow on genetic structure. In this study, by using maternally inherited chloroplast markers which can trace seed flow among populations $[6,29]$, we found that the effects of geographical isolation were significant in wild populations $(r=$ 0.4346, $P<0.0010$; Fig. 4$)$ but disappeared in cultivated populations $(r=0.0599, P=0.2710$; Fig. 4$)$. In addition, the haplotype distribution maps also visualize that common haplotypes are much more widespread in cultivated S. baicalensis than in wild populations. For example, HapG in wild populations (WTW, LCW, LPW, CD1W, SXW, and HXW) is mainly restricted to the central range of this species, whereas this haplotype occurred in 17 of 22 cultivated populations (Fig. 1). These patterns explicitly demonstrate that homogenization among cultivated populations and high within-population diversity should be mostly due to seed exchange mediated by human activities under cultivation.

\section{Conservation implications of $S$. baicalensis cultivation}

It has long been argued that traditional agriculture can serve as an important reservoir of genetic variability $[5,56]$. For example, by taking the jocote (Spondias purpurea), a small tree that bears fruit similar to tiny mongo in Mesoamerica, out of its natural, wild habitats and planting them in yards and other means of cultivation, farmers in the Mesoamerican region have helped to preserve the jocote's diversity [48]. Likewise, traditional cultivations is also an effective way for the maintenance and conservation of gene pools of medicinal plants, as evidenced by the studies of Guo et al. [15] and $\mathrm{He}$ et al. [16]. According to our investigation, the cultivation practices for $S$. baicalensis are also in traditional ways. Usually, farmers collected the seeds of $S$. baicalensis directly from local wild resources and then cultivated in the field. Sometimes, the germplasm can be dispersed to other places by their relatives or friends or by sale in the markets. Slight reduction of genetic diversity and little change of genetic composition in cultivated S. baicalensis, as well as a few specific haplotypes of cultivated group, confirm the effectiveness of saving plant diversity through local cultivation. This study further suggests that bringing wild medicinal plants into cultivation from different locations may help to widen the genetic background of cultivated populations, which will be beneficial for the sustainable utilization of natural resources.

Although cultivation is an effective strategy for preserving genetic resources of $S$. baicalensis, the wild resources still need to be protected in situ. This study did not find significant reduction of genetic diversity and apparent change of genetic composition in cultivated $S$. baicalensis, however, this pattern reflects mainly the changes of common haplotypes rather than rare alleles. In fact, 10 out of 25 haplotypes within wild populations have lost during the course of S. baicalensis cultivation. The results conform to the theoretical expectation that bottlenecks of short duration may have little effect on heterozygosity (here represented by haplotype diversity, $h_{\mathrm{T}}$ ) but will reduce severely the number of rare alleles [57]. Rare alleles are often considered a minor element in genetic conservation programs and yet they can be very important for long-term evolution or to meet new breeding objectives such as resistance to introduced insects or diseases [57]. It is therefore desirable to maintain rare alleles of $S$. baicalensis through in situ conservation of wild populations.

Seed exchange during the course of S. baicalensis cultivation exerts a significant impact on the genetic architecture of cultivated S. baicalensis and may also have profound implications for the conservation and utility of S. baicalensis germplasm. Genetic mixture induced by extensive seed exchange means that a fraction of cultivated populations may be sufficient to preserve most genetic variation of $S$. baicalensis. This will undoubtedly facilitate the conservation of genetic diversity of S. baicalensis through cultivation. However, numerous theoretical and empirical studies have suggested that genetic mixture of populations that are adapted to different local conditions could result in outbreeding depression, the reduction in fitness caused by the breakdown of coadapted gene complexes [58]. Extensive seed exchange may increase the risk of maladaptation and reduced growth or fertility resulting from maladaptation could reduce the success of cultivation projects and jeopardize the long-term survival of wild populations [59]. The evolutionary and practical consequences of extensive seed exchange of $S$. baicalensis are unknown so far, more studies are crucially needed to monitor the potentially negative impacts of seed exchange on the adaptation of wild populations and the growth of cultivated populations.

\section{Conclusions}

Facing the rapidly growing demands for medicinal plants, domestic cultivation is a viable and long-term way of protecting wild medicinal plant resources [3]. However, this study indicates that bringing a species into cultivation may impose profound impacts on 
genetic diversity patterns and even the evolutionary potentials of medicinal plants. Although the total genetic diversity maintained in cultivated $S$. baicalensis is comparable to wild populations due to the large initial population size and the short cultivation history, substantial rare alleles have lost and extensive seed exchange has caused the homogenization of cultivated populations during the course of cultivation. This study not only provides baseline data for preserving genetic resource of $S$. baicalensis through conservation-by-cultivation approach, but also represents a paradigm for evaluating the genetic impacts of recent cultivation on medicinal plants, which may be instructive to future cultivation projects of traditional Chinese medicinal plants.

Additional file 1: Chloroplast haplotype frequencies in 28 wild populations of Scutellaria baicalensis and 1 wild population of Scutellaria rehderiana.

Additional file 2: Chloroplast haplotype frequencies in 22 cultivated populations of Scutellaria baicalensis.

\section{Acknowledgements}

Special thanks go to Barbara Schaal for valuable suggestions on the manuscript and De-Zhu Li, Xiao-Quan Wang and Hua Peng for inspirational conversations. The authors appreciate Thomas Green and Qiao-Jun Jin for the language polish and Ming-Chun Peng for help in significant tests. We are grateful to field collaborators Xue-Feng Feng, Xiao-Guang Ge, ChengQiang Feng, Ji-Cheng Liu, Hui Zhang, Bing Wang, Xiu-Yu Lin, Yong-Qing Zhang, Xian-He Tan, Shui-Qing Chen, Xue-Mei Qin, Zhe-Zhi Wang and Ying-Dong Li. We also thank Xiao-Ming Li, Shu-Fang Lin, Qing-Mao Fang, Gui-Fang Fu, Mei-Lan Chen, and other members of Huang's group for experimental assistance. We are also indebted to three anonymous reviewers whose comments were of great help for improving the quality of this paper. This study was funded by the Projects of National Basic Research Program of China (2006CB504700), the Cultivation Programs for Young Scientists of Jiangxi Province (grants to Zhi-Yong Zhang, 2008DQ01500), the International Science and Technology Cooperation Program of China (2009DFA31660), and the China Postdoctoral Science Foundation (grants to Qing-Jun Yuan, 20090450551).

\section{Author details}

'Laboratory for Molecular Pharmaceutics, Institute of Chinese Materia Medica, China Academy of Chinese Medical Sciences, Beijing 100700, China. ${ }^{2}$ Laboratory of Subtropical Biodiversity, Jiangxi Agricultural University, Nanchang, Jiangxi 330045, China.

\section{Authors' contributions}

$\mathrm{L}-\mathrm{QH}$ conceived of the study and revised the manuscript. Q-JY performed sample collection, molecular experiment, data analysis and drafted the manuscript. Z-YZ contributed to the conception of the study, the writing and revision of the manuscript. JH participated in DNA extraction, PCR and sequencing. L-PG helped to coordinate the study and finish statistical tests. A-JS carried out partial sample collection. All authors read and approved the final manuscript.

\section{Authors' informations}

Prof. Lu-Qi Huang specializes in molecular pharmaceutics and the taxonomy of some systematically uncertain taxa in Chinese herbal medicine, such as Trichosanthes. Dr. Qing-Jun Yuan is interested in conservation genetics and domestication of cultivated medicinal plants. Prof. Zhi-Yong Zhang is working on molecular phylogeography and molecular systematics in the subtropical plants. Juan $\mathrm{Hu}$ is a master student studying the application of molecular markers in authentication of Chinese Materia Medica. Prof. LanPing Guo and Ai-Juan Shao are with special concerns about the sustainable utilization and conservation of natural medicinal resources.

Received: 28 September 2009 Accepted: 29 April 2010

Published: 29 April 2010

\section{References}

1. Vines G: Herbal Harvests with a Future: Towards Sustainable Sources for Medicinal Plants, Report for Plantlife International Salisbury, Wiltshire: The Wild Plant Conservation Charity 2004

2. WHO, IUCN, WWF: Guidelines on the Conservation of Medicinal Plants Gland Switzerland: International Union for Conservation of Nature and Natural Resources 1993.

3. Canter $\mathrm{PH}$, Thomas $\mathrm{H}$, Ernst E: Bringing medicinal plants into cultivation: opportunities and challenges for biotechnology. Trends Biotechnol 2005, 23:180-185.

4. Schippmann U, Leaman DJ, Cunningham AB: Impact of cultivation and gathering of medicinal plants on biodiversity: Global trends and issues. Biodiversity and the Ecosystem Approach in Agriculture, Forestry and Fisheries. Satellite event on the occasion of the Ninth Regular Session of the Commission on Genetic Resources for Food and Agriculture: 12-13 October 2002; Rome Inter-Departmental Working Group on Biological Diversity for Food and Agriculture. Rome: United Nations Food and Agriculture Organization 2002, 142-167.

5. Altieri MA, Merrick LC: In situ conservation of crop genetic resouces through maintenance of traditional farming systemas. Econ Bot 1987, 41:86-96.

6. Miller A, Schaal B: Domestication of a Mesoamerican cultivated fruit tree, Spondias purpurea. Proc Natl Acad Sci USA 2005, 102:12801-12806.

7. Anon: Conservation Impacts of Commercial Captive Breeding Workshop. Briefing Notes II. 7-9.12. Jacksonville Cambridge: IUCN/SSC Wildlife Trade Programme 2002.

8. Doebley JF, Gaut BS, Smith BD: The molecular genetics of crop domestication. Cell 2006, 127:1309-1321.

9. Blanca JM, Prohens J, Anderson GJ, Zuriaga E, Caòizares J, Nuez F: AFLP and DNA sequence variation in an Andean domesticate, pepino (Solanum muricatum, Solanaceae): implications for evolution and domestication. Am J Bot 2007, 94:1219-1229.

10. Campbell RK: Genecology of Douglas-fir in a watershed in Oregon cascades. Ecology 1979, 60:1036-1050.

11. Lefèvre F: Human impacts on forest genetic resources in the temperate zone: an updated review. Forest Ecol Manag 2004, 197:257-271.

12. McKay JK, Christian CE, Harrison S, Rice KJ: "How local is local?" A review of practical and conceptual issues in the genetics of restoration. Restor Ecol 2005, 13:432-440.

13. Gao W, Jia W, Gao X, Wang R, Xiao P: In vitro culture and cultivation of Chinese medicinal plants for industrial utilization and genetic resource conservation. Plant Genet Resour 2005, 3:116-126.

14. Jia W, Zhang L: Chinese herbal drug industry: past, present and future. Natural Products: Drug Discovery, Therapeutics, and Preventive Medicines Totowa, New Jersey: Humana PressZhang L, Demain AL 2005, 33-56.

15. Guo HB, Lu BR, Wu QH, Chen JK, Zhou TS: Abundant genetic diversity in cultivated Codonopsis pilosula populations revealed by RAPD polymorphisms. Genet Resour Crop Ev 2007, 54:917-924.

16. He J, Chen L, Si Y, Huang B, Ban X, Wang Y: Population structure and genetic diversity distribution in wild and cultivated populations of the traditional Chinese medicinal plant Magnolia officinalis subsp. biloba (Magnoliaceae). Genetica 2009, 135:233-243.

17. Shi W, Yang CF, Chen JM, Guo YH: Genetic variation among wild and cultivated populations of the Chinese medicinal plant Coptis chinensis (Ranunculaceae). Plant Biology 2008, 10:485-491.

18. Zhuravlev YN, Koren OG, Reunova GD, Artyukova EV, Kozyrenko MM, Muzarok TI, Kats IL: Ginseng conservation program in Russian Primorye: Genetic structure of wild and cultivated populations. J Ginseng Res 2004, 28:60-66.

19. Li XW, Hedge IC: Lamiaceae. Flora of China Beijing: Science Press \& St. Louis: Missouri Botanical Garden Press 1994, 17:93.

20. Huang S: Shen Nong Ben Cao Jing (The Divine Farmer's Materia Medica, translated by Yang SZ) Beijing: Traditional Chinese Medicine Ancient Books Press 1982. 
21. Chinese Pharmacopoeia Committee of People's Republic of China: Pharmacopoeia of the People's Republic of China Beijing: Chemical Industry Press 2005, 1:211.

22. Editorial Board of China Herbals: China Herbals Shanghai: Shanghai Science \& Technical Publisher 1998, 2:1682.

23. Huang JM, Wang CJ, Chou FP, Tseng TH, Hsieh YS, Hsu JD, Chu CY: Protective effect of baicalin on tert-butyl hydroperoxide-induced rat hepatotoxicity. Arch Toxicol 2005, 79:102.

24. Zhang DY, Wu J, Ye F, Xue L, Jiang S, Yi J, Zhang W, Wei H, Sung M, Wang W, Li X: Inhibition of cancer cell proliferation and prostaglandin $E_{2}$ synthesis by Scutellaria baicalensis. Cancer Res 2003, 63:4037.

25. Craker LE, Giblette J: Chinese Medicinal Herbs: Opportunities for Domestic Production. Trends in new crops and new uses Alexandria, VA: ASHS PressJanick J, Whipkey A 2002, 491-496.

26. China List of National Key Protected Wild Medicinal Species (1987). [http://vip.chinalawinfo.com/Newlaw2002/SLC/slc.asp?db=chl\&gid=34091].

27. Ran MX, Zhou HQ: Guidelines on Modern Cultivation, Breeding and Processing of Chinese Materia Medica Beijing: China Traditional Chinese Medicine Press 1999.

28. Schaal BA, Hayworth DA, Olsen KM, Rauscher JT, Smith W: Phylogeography studies in plants: problems and prospects. Mol Ecol 1998, 7:465-474.

29. Londo JP, Chiang YC, Huang KH, Chiang TY, Schaal BA: Phylogeography of Asian wild rice, Oryza rufipogon, reveals multiple independent domestications of cultivated rice, Oryza sativa. Proc Natl Acad Sci USA 2006, 103:9578-9583.

30. Doyle JJ, Doyle JL: A rapid DNA isolation procedure for small quantities of fresh leaf tissue. Phytochem Bull 1987, 19:11-15.

31. Hamilton MB: Four primer pairs for the amplification of chloroplast intergenic regions with intraspecific variation. Mol Ecol 1999, 8:521-522.

32. Sang T, Crawford DJ, Stuessy TF: Chloroplast DNA phylogeny, reticulate evolution, and biogeography of Paeonia (Paeoniaceae). Am J Bot 1997, 84:1120-1136.

33. Thompson JDTJ, Gibson PF, Jeanmougin F, Higgins DG: The windows interface: Flexible strategies for multiple sequence alignment aided by quality analysis tools. Nucleic Acids Res 1997, 24:4876-4882

34. Caicedo AL, Schaal BA: Population structure and phylogeography of Solanum pimpinellifolium inferred from a nuclear gene. Mol Ecol 2004, 13:1871-1882.

35. Tajima F: Statistical method for testing the neutral mutation hypothesis by DNA polymorphism. Genetics 1989, 123:585-595.

36. Fu YX, Li WH: Statistical tests of neutrality of mutations. Genetics 1993 133:693-709.

37. Rozas J, Sanchez-DelBarrio JC, Messeguer X, Rozas R: DnaSP, DNA polymorphism analyses by the coalescent and other methods. Bioinformatics 2003, 19:2496-2497.

38. Clement M, Posada D, Crandall KA: TCS: a computer program to estimate gene genealogies. Mol Ecol 2000, 9:1657-1659.

39. Templeton AR, Crandall KA, Sing CF: A cladistic analysis of phenotypic associations with haplotypes inferred from restriction endonuclease mapping and DNA sequence data. III. Cladogram estimation. Genetics 1992, 132:619-633.

40. Kimura M: A simple method for estimating evolutionary rate of base substitutions through comparative studies of nucleotide sequences. J Mol Evol 1980, 16:111-120.

41. Kumar S, Tamura K, Nei M: MEGA3: Integrated software for Molecular Evolutionary Genetics Analysis and sequence alignment. Brief Bioinform 2004, 5:150-163.

42. Nei M, Kumar S: Molecular Evolution and Phylogenetics New York: Oxford University Press 2000.

43. Jensen $J$, Bohonak AJ, Kelley ST: Isolation By Distance Web Service. BMC Genet 2005, 6:13, v13.11.

44. Olsen KM, Schaal BA: Evidence on the origin of cassava: Phylogeography of Manihot esculenta. Proc Natl Acad Sci USA 1999, 96:5586-5591.

45. Olsen KM, Gross BL: Detecting multiple origins of domesticated crops. Proc Natl Acad Sci USA 2008, 105:13701-13702.

46. Allaby RG: The rise of plant domestication: Life in the slow lane. Biologist 2008, 55:94-99.

47. Kilian B, Ozkan H, Walther A, Kohl J, Dagan T, Salamini F, Martin W: Molecular diversity at 18 loci in 321 wild and 92 domesticate lines reveal no reduction of nucleotide diversity during Triticum monococcum (einkorn) domestication: Implications for the origin of agriculture. $\mathrm{Mol}$ Biol Evol 2007, 24:2657-2668.

48. Miller AJ, Schaal BA: Domestication and the distribution of genetic variation in wild and cultivated populations of the Mesoamerican fruit tree Spondias purpurea L. (Anacardiaceae). Mol Ecol 2006, 15:1467-1480.

49. Institute of Medicinal Plant Development in Chinese Academy of Medical Sciences: Cultivation of Medicinal Plants in China Beijing: Agriculture Press 1991.

50. Björnerfeldt $S$, Webster MT, Vilà C: Relaxation of selective constraint on dog mitochondrial DNA following domestication. Genome Biol 2006, 16:990-994.

51. Tang T, Shi S: Molecular population genetics of rice domestication. J Integr Plant Biol 2007, 49:769-775.

52. Ellstrand NC, Marshall DL: The impact of domestication on distribution of allozyme variation within and among cultivars of radish, Raphanus sativus L. Theor Appl Genet 1985, 69:393-398.

53. Hamrick JL, Godt MJW: Allozyme diversity in cultivated crops. Crop SCi 1997, 37:26-30.

54. Brown AHD: Isozymes, plant population genetic structure and genetic conservation. Theor Appl Genet 1978, 52:145-157.

55. Hyten DL, Song Q, Zhu Y, Choi IY, Nelson RL, Costa JM, Specht JE, Shoemaker RC, Cregan PB: Impacts of genetic bottlenecks on soybean genome diversity. Proc Natl Acad Sci USA 2006, 103:16666-16671.

56. Vargas-Ponce O, Zizumbo-Villarreal D, Martinez-Castillo J, Coello-Coello J, Colunga-Garcia Marin P: Diversity and structure of landraces of Agave grown for spirits under traditional agriculture: A comparison with wild populations of $A$. angustifolia (Agavaceae) and commercial plantations of A. tequilana. Am J Bot 2009, 96:448-457.

57. Allendorf FW, Luikart G: Conservation and the Genetics of Populations Oxford: Blackwell Publishing, Malden, MA 2007, 117-141.

58. Storfer A: Gene flow and endangered species translocations: a topic revisited. Biol Consen 1999, 87:173-180.

59. Bower AD, Aitken SN: Ecological genetics and seed transfer guidelines for Pinus albicaulis (Pinaceae). Am J Bot 2008, 95:66-76.

doi:10.1186/1471-2156-11-29

Cite this article as: Yuan et al:: Impacts of recent cultivation on genetic diversity pattern of a medicinal plant, Scutellaria baicalensis (Lamiaceae) BMC Genetics 2010 11:29.

\section{Submit your next manuscript to BioMed Central and take full advantage of:}

- Convenient online submission

- Thorough peer review

- No space constraints or color figure charges

- Immediate publication on acceptance

- Inclusion in PubMed, CAS, Scopus and Google Scholar

- Research which is freely available for redistribution

Submit your manuscript at www.biomedcentral.com/submit
BioMed Centra 